\title{
Article
}

\section{Online Interactive Teaching Modules Enhance Quantitative Proficiency of Introductory Biology Students}

\author{
Katerina V. Thompson, ${ }^{*}$ Kären C. Nelson, ${ }^{\dagger}$ Gili Marbach-Ad, ${ }^{*}$ Michael Keller, ${ }^{*}$ \\ and William F. Fagan ${ }^{+}$
}

*College of Chemical and Life Sciences and 'Department of Biology, University of Maryland, College Park, MD 20742

Submitted March 15, 2010; Revised June 8, 2010; Accepted June 20, 2010

Monitoring Editor: John Jungck

\begin{abstract}
There is widespread agreement within the scientific and education communities that undergraduate biology curricula fall short in providing students with the quantitative and interdisciplinary problemsolving skills they need to obtain a deep understanding of biological phenomena and be prepared fully to contribute to future scientific inquiry. MathBench Biology Modules were designed to address these needs through a series of interactive, Web-based modules that can be used to supplement existing course content across the biological sciences curriculum. The effect of the modules was assessed in an introductory biology course at the University of Maryland. Over the course of the semester, students showed significant increases in quantitative skills that were independent of previous math course work. Students also showed increased comfort with solving quantitative problems, whether or not they ultimately arrived at the correct answer. A survey of spring 2009 graduates indicated that those who had experienced MathBench in their course work had a greater appreciation for the role of mathematics in modern biology than those who had not used MathBench. MathBench modules allow students from diverse educational backgrounds to hone their quantitative skills, preparing them for more complex mathematical approaches in upper-division courses.
\end{abstract}

\section{INTRODUCTION}

Consensus is growing within the scientific and academic communities that undergraduate biological science curricula are in need of substantial reform (National Research Council [NRC], 2003, 2009; Steen, 2005; Project Kaleidoscope, 2006). Interdisciplinary and multidisciplinary approaches now dominate the forefront of biological sciences research at every level, from nanobiotechnology to ecosystem dynamics, but undergraduate curricula remain essentially disciplinary in nature. Mathematics and quantitative approaches in particular clearly constitute a key tool for modern life scientists, yet the undergraduate curriculum fails to help students appreciate the

DOI: $10.1187 /$ cbe.10-03-0028

Address correspondence to: Katerina Thompson (kaci@umd.edu).

(C) 2010 K. V. Thompson et al. CBE-Life Sciences Education (C) 2010 The American Society for Cell Biology. This article is distributed by The American Society for Cell Biology under license from the author(s). It is available to the public under an Attribution-Noncommercial-Share Alike 3.0 Unported Creative Commons License (http://creativecommons.org/licenses/by-nc-sa/3.0). important relationships between mathematics and modern biology (Gross, 2000; Ewing, 2002; Hastings and Palmer, 2003; Cohen, 2004; Hoy, 2004; Jungck, 2005; Steen, 2005). Biology courses remain largely qualitative and descriptive rather than rigorously quantitative. Lack of quantitative training among our biology majors weakens students at a practical level, whether they plan to analyze environmental impacts (e.g., minimum viable population size) or pursue a career in medicine (e.g., nonlinear drug dose responses, Yuan, 2005).

Currently, biology undergraduates at many four-year institutions have few requirements relative to mathematics, far fewer than those in other sciences such as physics or chemistry. Although biology majors typically take math through calculus, these courses often use nonbiological examples or abstractions (Gross, 1994) and rarely teach other mathematical skills essential for modern biology (NRC, 2003). Many institutions have addressed this by developing special courses (capstone courses, advanced undergraduate seminars, or special research tracks) that introduce elite students to quantitative biology. Such courses undoubtedly produce excellent cutting-edge scholarship, but they are limited to only the strongest students and thus do not help to 
transform the culture of biology teaching and learning. A stronger approach, and one that is more likely to heal the damaging disjunction between mathematics and biology, is to infuse math throughout the entire undergraduate biology curriculum for all students (Gross, 2004; Labov et al., 2010).

Online modules (free-standing instructional elements, often Web-based, that can be used by multiple instructors and revisited throughout a course sequence) have become a key educational tool to integrate mathematics and biology. MathBench Biology Modules were designed to integrate quantitative approaches and mathematics more deeply into the introductory biology curriculum in a way that would reinforce biological concepts, increase math literacy, and prepare students to be receptive to more complicated mathematical approaches in upper-level courses (Nelson et al., 2009). The MathBench suite consists of 37 self-contained learning modules that use an informal tone to combat math anxiety and leverage the students' pre-existing knowledge of math. We developed the modules in alignment with generally accepted best practices in online instruction, including embedding concepts within storylines (Parker and Lepper, 1992; Mayer, 2008), using informal language (Ross, 1983; d'Ailly et al., 1997; Moreno and Mayer, 2000), proving opportunities for self-calibration (Hannafin and Sullivan, 1996), and striking a balance between demonstrating solutions to problems and allowing students to practice finding the solutions themselves (Hannafin and Sullivan, 1996). Each MathBench module consists of 8-30 interlinked, well-illustrated Web pages focusing on a single quantitative theme (e.g., diffusion, Punnett squares, data visualization, log transformations) plus interactive problems, interactive graphics, and quizzes to measure student comprehension. The quiz questions can be drawn randomly from a larger bank of test questions, allowing for individualized grading opportunities even in largeenrollment classes. MathBench modules are freely available online at mathbench.umd.edu.

\section{MATERIALS AND METHODS}

The impact of MathBench Biology Modules on undergraduate student quantitative skills was evaluated during the fall 2009 semester in a large introductory biology course at the University of Maryland, College Park. The course was BSCI 105 Principles of Biology 1: Cell and Molecular Biology, with a total enrollment of 614 students. The course was subdivided into five separate lecture sections of between 42 and 155 students, each taught by a different faculty member. Each lecture section was further subdivided into laboratory sections of approximately 20 students each, which met once each week for $3 \mathrm{~h}$. Although BSCI 105 is designed for biology majors, it is also required in several other degree programs (e.g., chemistry, kinesiology, nutrition) and is taken by students from a wide variety of majors to fulfill medical school application requirements.

A series of nine MathBench modules was incorporated into the BSCI 105 laboratory curriculum. The modules were designed to introduce and reinforce specific quantitative skills and concepts that were identified by our faculty as being important for success in modern biology (Table 1). Modules covered topics such as basic lab techniques (metric system and use of the micropipetor), developing standard curves, logarithmic functions (particularly with respect to understanding $\mathrm{pH}$ ), calculating molar weight, visualizing three-dimensional structures in two dimensions, probability calculations necessary for understanding BLAST searches, basic graphing (bar graphs, log), and simple statistical analyses. For example, the module entitled "Normal Distributions and the Scientific Method" begins with a brief overview of hypothesis testing, emphasizing the need for measuring outcomes, replicating measurements, and making comparisons. The module then uses a fanciful hypothetical scenario (the role of Fish2Whale fish food in increasing body length of tropical fish) to introduce students to the idea of characterizing variable traits within a population, such as organism size, using mean and SD. An interactive applet

Table 1. MathBench modules used and specific quantitative skills and concepts emphasized in each

\begin{tabular}{|c|c|c|c|c|c|c|c|c|c|c|}
\hline & $\begin{array}{c}\text { Distill } \\
\text { biology } \\
\text { into math }\end{array}$ & $\begin{array}{c}\text { Use } \\
\text { equations }\end{array}$ & $\begin{array}{l}\text { Use } \\
\text { graphs }\end{array}$ & $\begin{array}{c}\text { Fundamental } \\
\text { equations }\end{array}$ & Magnitude & $\begin{array}{c}\text { Unit } \\
\text { conversions }\end{array}$ & Probability & Statistics & $\begin{array}{c}\text { Model } \\
\text { structure/ } \\
\text { iteration }\end{array}$ & $\begin{array}{l}\text { Rates and } \\
\text { equilibrium }\end{array}$ \\
\hline \multicolumn{11}{|l|}{ Measurement } \\
\hline Basic lab techniques & $X$ & $X$ & $X$ & $\mathrm{X}$ & & $X$ & & & & $X$ \\
\hline $\begin{array}{l}\text { Straight lines / } \\
\text { standard curves }\end{array}$ & $X$ & $X$ & $x$ & $X$ & & & & & & $x$ \\
\hline Logs and $\mathrm{pH}$ & $x$ & $X$ & & $X$ & $X$ & & & & & $x$ \\
\hline $\begin{array}{l}\text { Calculating molar } \\
\text { weight }\end{array}$ & $x$ & $x$ & & & & $X$ & & & & \\
\hline \multicolumn{11}{|l|}{ Visualization } \\
\hline A graphing primer & $x$ & $x$ & $X$ & & & & & & & $\mathrm{X}$ \\
\hline Log transformations & $x$ & $X$ & $X$ & $x$ & $X$ & & & & & \\
\hline \multicolumn{11}{|l|}{ Probability and statistics } \\
\hline $\begin{array}{l}\text { Normal distributions } \\
\text { and the scientific } \\
\text { method }\end{array}$ & $x$ & & $X$ & & & & $x$ & $X$ & $x$ & \\
\hline Bar graphs and SEs & $\mathrm{X}$ & $\mathrm{X}$ & $x$ & & & & & $\mathrm{x}$ & & \\
\hline $\begin{array}{l}\text { BLAST and } \\
\text { (im)probability }\end{array}$ & $x$ & & & & $X$ & $X$ & $x$ & & & \\
\hline
\end{tabular}




\section{Comparing 2 Normal Distributions}
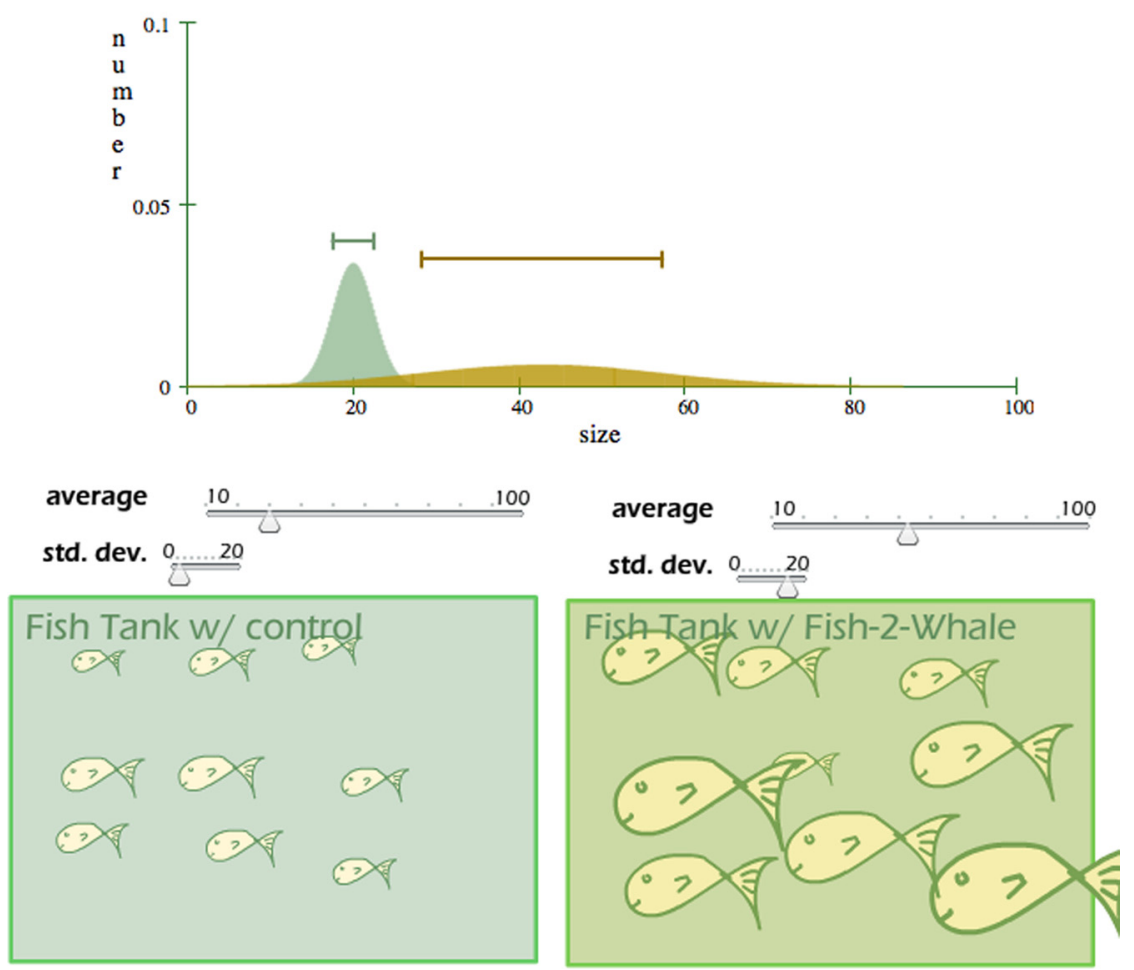

Figure 1. Screen shot from the "Normal Distributions and the Scientific Method" module. imbedded within the module allows students to manipulate these parameters and watch the effect of these manipulations directly on a virtual population of fish and graphically on a distribution of fish body lengths. Students are guided through their explorations with a systematic series of questions. At the conclusion of the module, students have the opportunity to manipulate means and standard deviations independently for two groups of virtual fish, representing control and treatment groups, allowing them to see the impact of these parameters on a scientist's ability to draw robust conclusions from an experiment (Figure 1).

Students were assigned modules at predetermined intervals throughout the fall semester. Each of the nine modules was developed to complement a specific laboratory exercise, so that students made immediate practical use of what they had learned. Modules were completed as homework, outside of class time. Each module was followed by a quiz, which was administered online through the campus course management system. Student quiz scores in total constituted $16 \%$ of the laboratory course grade.

\section{Quantitative Skill Survey Design and Administration}

To measure changes in quantitative skills over the course of the semester, we developed an 18-question pretest instrument that touched upon nine of our 10 specific quantitative skills (Table 1). We did not create specific questions for the skill "Distill biology into math," as it represented the overarching goal of the project and would presumably be reflected in changes in total scores between the pretest and the posttest. The questions were crafted to allow each quantita- tive skill to be evaluated along a cognitive spectrum (Mayer, 2002), with one question designed to measure basic understanding and the other designed to reflect a more sophisticated understanding. For each question, students could select one of four multiple-choice options, or they could answer "I do not know how to approach this problem." The "I do not know..." option was included as a way of assessing the students' degree of comfort with solving quantitative problems, whether or not they ultimately arrived at the correct answer. Before its use in this study, the instrument was piloted in introductory biology and genetics classes to establish internal consistency, criterion validity, and content validity (Garson, 2007). A second version, with the same 18-question structure but differing only slightly in numerical details, was created to serve as a posttest. The posttest also asked students to reflect on whether their quantitative skills had improved as a result of the introductory biology course and, if so, which components of the course curriculum were responsible for the improvement. The posttest also contained two open-ended questions that allowed students to provide feedback on the modules and their implementation.

Students in BSCI 105 were asked to complete the pretest during the first two weeks of the semester, before the first MathBench module was assigned. At the end of the semester, following the completion of all MathBench modules and quizzes, they were asked to complete the posttest. Analyses of changes over the course of the semester included only those students who completed both the pretest and the posttest $(n=204)$. Analyses of self-reported assessments of improvement in quantitative skill used all students who completed the posttest $(n=396)$. 


\section{Survey of Attitudes in Graduates}

In an effort to assess longer-term impacts of the MathBench initiative on student attitudes regarding the relationship between math and biology, we added several questions to an existing survey routinely administered to all graduating seniors in the College of Chemical and Life Sciences. Between 2005 and 2009, MathBench modules had been gradually introduced into selected sections of four introductorylevel courses typically taken in the first two years of the biological sciences curriculum (Principles of Biology I, II, and III, and Principles of Genetics). Spring 2009 graduates $(n=307)$ were first asked whether they had used MathBench modules in any of their courses. Because MathBench had only been integrated into the curriculum fairly recently and had not yet been fully implemented, we expected that a large proportion of the graduating seniors would not have encountered it as part of their course work. They were then asked to select the statement that most closely represented their attitude toward math ("I hate math and try to avoid it," "I don't like math but I can cope with it," "I don't care about math one way or another," "I like math but I don't seek it out," or "I like math and enjoyed having course work that included math") and to describe their attitude regarding the relationship between math and biology ("Math is not relevant to biology," "Math can be useful in biology but it's not really necessary," "Math is helpful in biology," "Math is essential in biology if you want to do cutting-edge work," or "Math is essential for doing any biology, cutting-edge or not"). Attitudes of students who had encountered MathBench in their course work were then compared with those who had not.

\section{Data Analysis}

Pre- and posttest data were matched for all students completing both tests. We augmented the data set with the students' math eligibility level (determined by a math eligibility test administered by the university at orientation and completion of college mathematics course work) and whether or not they were concurrently enrolled in a math class. All statistical tests (multiple analysis of variance [MANOVA], Pearson productmoment correlation, Chi-square) were performed using JMP version 8.0.2.

\section{RESULTS}

Students showed significant improvement in quantitative skills over the course of the semester (pretest $x=7.3$ correct out of 18 , posttest $x=10.4$ correct; repeated measures MANOVA $\mathrm{F}_{1196}=125.4040, p<0.0001$ ). There was a significant effect of math eligibility on pre- and posttest scores, with students eligible for precalculus having the lowest scores and students eligible for calculus 3 or higher having the highest scores $\left(\mathrm{F}_{3196}=11.0634, p<0.0001\right.$; Figure 2). Nonetheless, the magnitude of improvement in scores between the pre- and posttest was independent of math eligibility $\left(\mathrm{F}_{3196}=0.4764\right.$, NS). Students who were concurrently enrolled in a math class showed slightly, but significantly, greater improvements in scores than those not concurrently enrolled in math $\left(\mathrm{F}_{1196}=6.2077, p<0.05\right.$; Figure 3$)$. Overall, the improvement in score from pre- to posttest was nega-

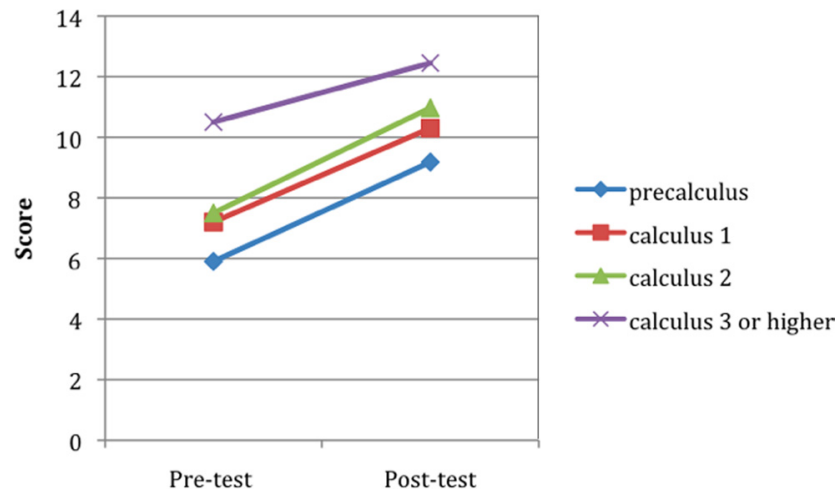

Figure 2. Changes in scores across the semester on an 18-item quantitative assessment for introductory biology students eligible for different levels of mathematics classes (precalculus, $\mathrm{n}=51$; calculus $1, \mathrm{n}=85$; calculus $2, \mathrm{n}=53$; or calculus 3 or higher, $\mathrm{n}=15$ ).

tively correlated with pretest score, indicating that students with lower initial scores made more dramatic gains (Pearson product-moment correlation, $\mathrm{r}=-0.657, \mathrm{n}=204, \mathrm{p}<$ 0.0001).

Students did not show uniform improvement across all questions. When the questions were sorted by the proportion of students who answered them correctly, the largest gains were seen in the 12 questions that were most likely to be answered correctly on the pretest (i.e., the "easiest" questions; Figure 4). Little or no improvement was seen on the six questions that the students were least likely to have answered correctly on the pretest (the "hardest" questions).

Math eligibility significantly affected level of risk aversion, as measured by the frequency with which students responded "I don't know how to approach this problem." Overall, 75\% of students answered "I don't know..." to at least one pretest question, whereas $29 \%$ so answered on the posttest. Students having low math eligibility were most risk averse (repeated measures MANOVA $\mathrm{F}_{3196}=5.6801, p<$ $0.01)$. As a whole, students were less risk averse after com-

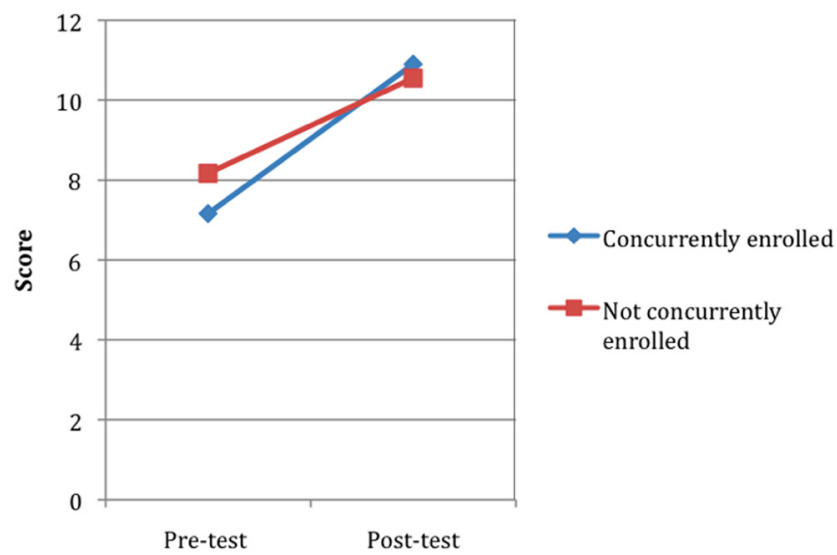

Figure 3. Changes in scores across the semester on an 18-item quantitative assessment for introductory biology students concurrently enrolled in a math class $(n=79)$ or not concurrently enrolled in a math class $(\mathrm{n}=125)$. 


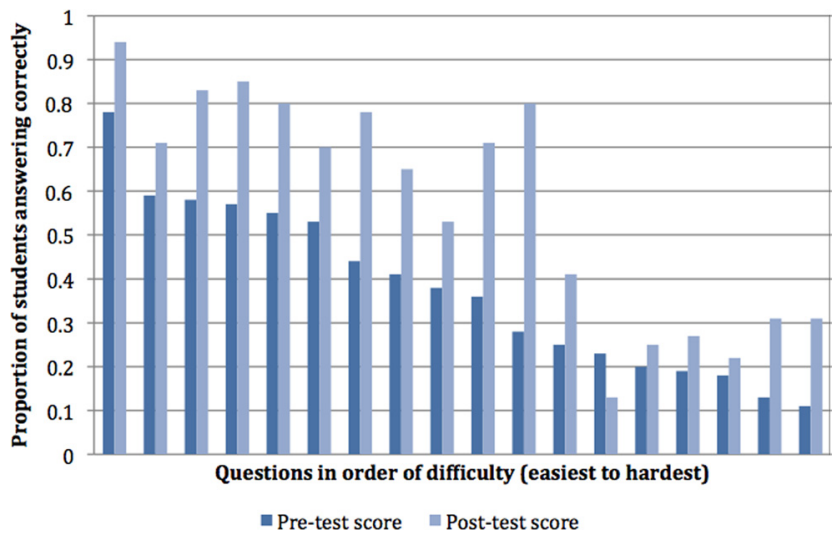

Figure 4. Proportion of students answering correctly on the preand posttests for each of 18 questions on a quantitative skills assessment, with questions sorted by the proportion of students answering correctly on the pretest.

pleting the MathBench modules, as evidenced by a significant decrease in the frequency of "I don't know..." responses between the pre- and the posttests $\left(\mathrm{F}_{1196}=80.578\right.$, $p<0.0001)$. The greatest decreases in risk aversion were seen in the students with the lowest math eligibility $\left(\mathrm{F}_{3196}=\right.$ $4.7257, p<0.005)$ and those concurrently enrolled in a math course $\left(\mathrm{F}_{1196}=4.0114, p<0.05\right)$.

In the posttest, students were asked whether they had experienced an improvement in quantitative skills as a result of the course. Most students indicated that they had experienced "little" or "moderate" improvement (Figure 5). Of the students who reported improvement in quantitative skills (367 of 396 , or $93 \%$ of students who completed the posttest), $71 \%$ attributed this improvement to the MathBench modules (Figure 6).

Student comments to the open-ended question, "What role did the MathBench modules have in the development of your scientific content knowledge and quantitative skills?" were overwhelmingly positive ( $83 \%$ of responses). Many students $(31 \%)$ indicated that the modules helped them re-

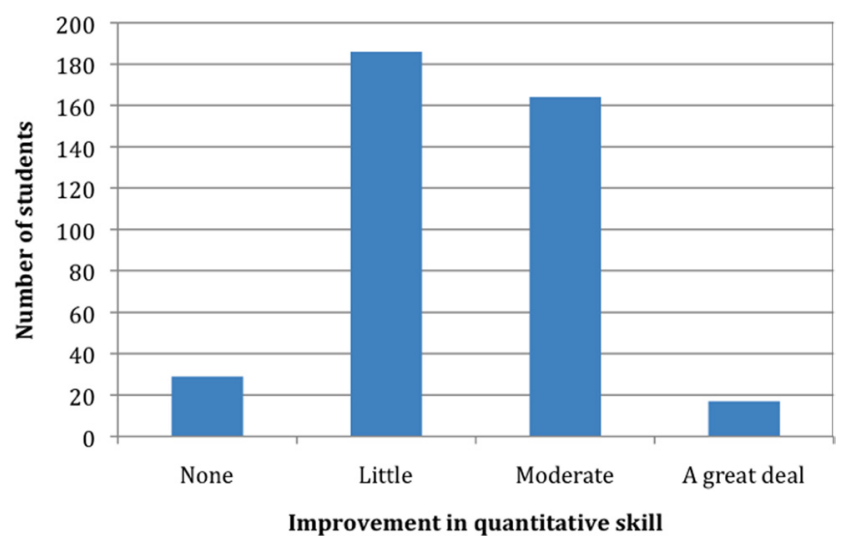

Figure 5. Self-reported improvement in quantitative skills across the fall 2009 semester by students enrolled in introductory biology BSCI $105(\mathrm{n}=396)$.

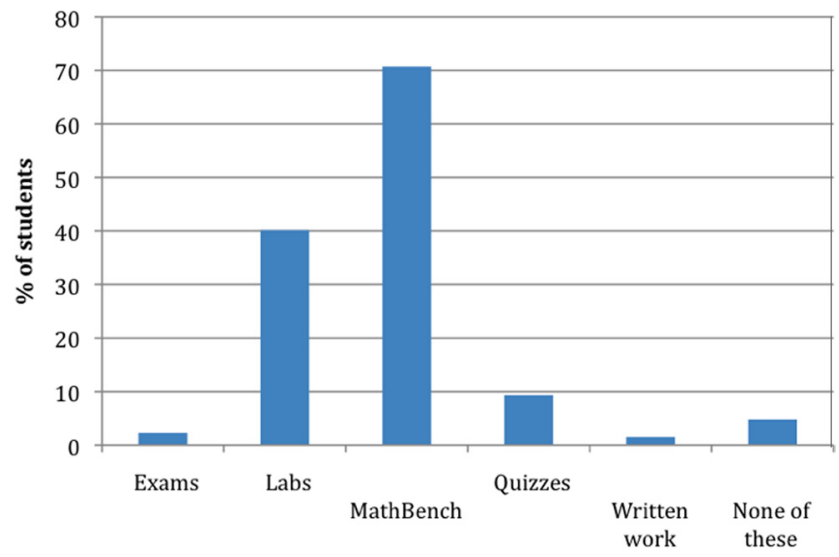

Figure 6. Student perceptions of BSCI 105 course components that contributed to improvement in quantitative skills $(n=367$; percentages sum to $>100 \%$ because students could select multiple answers).

fresh their understanding of material learned in previous courses and high school. "The MathBench Biology Modules helped my content knowledge and quantitative skills by reviewing previous math skills I learned and elaborating on these skills to take my understanding of science-related math to another level." A small percentage of students (9\%), largely those with more advanced mathematics backgrounds, found the modules too informal and simplistic. However, there were many positive comments from other students who appreciated those features (e.g., "its humorous style of writing and funny images make it easier to study without any pressure," "MathBench modules improved my quantitative skills because they made it very easy to see what the math was, they had good examples and explained all the math visually which really helped me"). Specific design features that students found helpful were its interactivity, opportunities for practice, immediate self-assessment feedback, and the ability of students to proceed at their own pace. "It helped to have interactive examples within the modules that allowed me to test my knowledge throughout the lesson." "I found it easier to go at my own pace with the modules rather than being in a classroom setting where I find it difficult to comprehend the material as quickly as the other students." Some indicated that the modules increased their level of engagement with the class (e.g., "I enjoyed the MathBench modules because during the week it kept me constantly active with the Bio class"). Many students specifically mentioned that they had a greater appreciation for the role of math in the biological sciences (e.g., "I now better understand the connection between math and Biology").

About half $(51 \%)$ of the Spring 2009 graduates had encountered the modules in their course work. Regardless of their exposure to MathBench, a large majority of graduates (74\%) either enjoyed or actively sought mathematical content in their course work. Graduates who had used MathBench were significantly more likely to describe the relationship between math and biology as "essential to cutting-edge biology" or "essential for all fields of biology" $\left(\chi^{2}=13.7\right.$, $\mathrm{df}=2, p<0.001 ;$ Figure 7). 


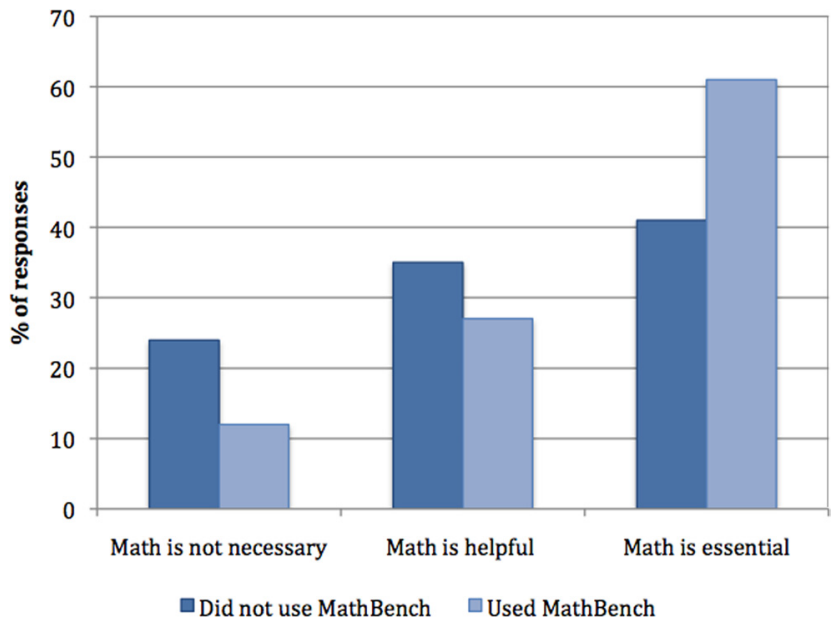

Figure 7. Responses of 2009 biological sciences graduates $(\mathrm{n}=$ $307)$ to a survey question regarding their attitude regarding the relationship between math and biology.

\section{DISCUSSION}

MathBench Biology Modules were effective in introducing and reinforcing quantitative concepts and skills into a largeenrollment introductory biology course. Over the course of the semester, students showed significant increases in quantitative skill that were independent of previous math course work. Specific attributes that students felt contributed to the development of their quantitative skills included interactivity, use of humor and informal language, opportunities for practice, immediate self-assessment feedback, and the ability of students to proceed at their own pace. This integration of mathematical approaches into biology courses appears to have lasting effects on student attitudes, as graduating seniors who encountered MathBench in their introductory course work reported a greater appreciation of the essential role of mathematics in the biological sciences than those who had not used MathBench.

Our findings are consistent with previous research that indicates that computers facilitate active learning and increase student interest and motivation, allowing them to gain a deeper understanding of complex technical information (American Association for the Advancement of Science, 1993, Weglinsky, 1998; Mayer, 2002; NRC, 2003). Computerassisted instruction may be particularly advantageous for certain groups of otherwise disadvantaged students (Cotton, 1991), such as low-achieving students (Edwards et al., 1975; Bangert-Drowns et al., 1985; Roblyer et al., 1988) and economically disadvantaged students (Ragosta et al., 1982). These gains seem to come from the ability of students to work at their own pace and receive as much assistance as they require (Robertson et al., 1987).

These techniques are also thought to help the approximately one-third of college students who have trouble with quantitative work because of "math anxiety" (Betz, 1978). In our study, students with less-well-developed quantitative skills at the beginning of the semester (i.e., low math eligibility) were significantly more likely than those with stronger quantitative skills to avoid answering specific problems on the quantitative assessment. By the end of the semester, they showed increased comfort with solving quantitative problems, whether or not they ultimately arrived at the correct answer. Many of their comments on the open-ended assessment questions indicated that they felt more confidence in applying math to biological problems. This is heartening, especially in light of recent data that show that students with weak quantitative skills are wary of attempts to infuse mathematical approaches into introductory biology courses (Matthews et al., 2009).

Although students showed improvement across a range of quantitative skills and concepts, little to no improvement was seen in the "hardest" items on the assessment instrument. This result is not entirely surprising, given that the modules evaluated in this study were developed specifically for use in an introductory level course and therefore were designed to provide a basic level of conceptual understanding. It remains an open question whether this online modular approach is similarly effective in deepening quantitative understanding in more advanced course work. There is some evidence that the effectiveness of various pedagogical techniques differs depending on whether the intended audience is composed mainly of "novice" or "expert" learners, with many best practices shifting markedly for a more experienced audience (the so-called "expertise reversal effect," sensu Clark and Mayer, 2008).

Online modules are now widely used in quantitative biology. Some were written before technological tools for interactivity were widespread. Others, (e.g., ESTEEM and COMAP) include minimal explanatory text, couch explanations in formal language, and are best suited for upperdivision students. MathBench modules differ in their approach, using simple, clear, and intuitive explanations of the math involved to help students bridge the gap between biology and mathematical formalism. As such, MathBench modules are complementary with many existing modulesindeed, other modules largely begin where MathBench leaves off. The modules' easy accessibility makes it possible for them to be disseminated widely in a variety of educational contexts, and their design is inclusive of diverse learning styles and educational backgrounds, making them a useful tool for preparing students for the complex mathematical approaches that have become essential to modern biology.

\section{ACKNOWLEDGMENTS}

We are grateful to all the faculty who helped develop ideas for the modules and used them in their classes. We also thank Leslie Ries, Katie Schneider, Tanya McLean, David Boothe, Aleksandra Ogurtsova, Awais Malik, Li Zhu, and Mike Landavere for their help in developing the modules and GoEun $\mathrm{Na}$ for assistance with pre- and posttest validation. Two anonymous reviewers provided feedback that greatly improved the manuscript. Support for this project was provided by a Howard Hughes Medical Institute Undergraduate Science Education Program grant to the University of Maryland; a National Science Foundation Course; Curriculum, and Laboratory Improvement grant (DUE-0736975); an instructional improvement grant from the University of Maryland Center for Teaching Excellence; and the College of Chemical and Life Sciences. 


\section{REFERENCES}

American Association for the Advancement of Science (1993). Benchmarks for Science Literacy. New York: Oxford University Press.

Bangert-Drowns, R. L., Kulik, J. A., and Kulik, C. C. (1985). Effectiveness of computer-based education in secondary schools. J. Comp.-Based Instr. 12, 59-68.

Betz, N.E. (1978). Prevalence, distribution, and correlates of math anxiety in college students. J. Couns. Psychol. 25, 441-448.

Clark, R. C., and Mayer, R. E.. (2008). E-Learning and the Science of Instruction, 2nd ed. San Francisco, CA: Pfeiffer Wiley.

Cohen, J. E. (2004). Mathematics is biology's next microscope, only better; biology is mathematics' next physics, only better. PLoS Biol. 2, e439.

Cotton, K. (1991). Computer-Assisted Instruction. School Improvement Research Series Close-Up \#10, NorthWest Regional Educational Laboratory.

d'Ailly, H. H., Simpson, J., and MacKinnon, G. E. (1997). Where should "you" go in a math compare problem? J. Educ. Psychol. 89, 562-567.

Edwards, J., Norton, S., Taylor, S, Weiss, M., and Dusseldorp, R. (1975). How effective is CAI? A review of the research. Educ. Leadersh. 33, 147-153.

Ewing, J. (2002). The next big thing in mathematics. Chron. High. Educ. Sept. 20.

Garson, D. (2007). Validity. http:/ / faculty.chass.ncsu.edu/garson/ PA765/validity.htm (accessed 14 March 2010).

Gross, L. (1994). Quantitative training for life-science students. Bioscience 44,59 .

Gross, L. (2000). Education for a biocomplex future. Science 28, 807.

Gross, L. J. (2004). Points of view: the interface of mathematics and biology: interdisciplinarity and the undergraduate biology curriculum: finding a balance. Cell Biol. Educ. 3, 85-87.

Hannafin, R. D., and Sullivan, H. J. (1996). Preferences and learner control over amount of instruction. J. Educ. Psychol. 88, 162-173.

Hastings, A., and Palmer, M. A. (2003). Mathematics and biology: a bright future for biologists and mathematicians? Science 299, 5615.

Hoy, R. (2004). Points of view: the interface of mathematics and biology: new math for biology is the old new math. Cell Biol. Educ. 3, 90-92.

Jungck, J.R. (2005). Challenges, connection, complexities: educating for collaboration. In: Math \& Bio 2010: Linking Undergraduate Disciplines, ed. L.A. Steen, Washington, DC: Mathematical Association of America, 1-12.

Labov, J. B., Reid, A. H., and Yamamoto, K. R. (2010). Integrated biology and undergraduate science education: a new biology education for the twenty-first century? CBE Life Sci. Educ. 9, 10-16.
Matthews, K. E., Abrams, P., and Goos, M. (2009). Putting it into perspective: mathematics in the undergraduate science curriculum. Int. J. Math. Ed. Sci. Tech. 40, 891-902.

Mayer, R.E. (2002). Rote versus meaningful learning. Theory Into Practice 41, 226-232.

Mayer, R.E. (2008). Learning and Instruction. 2nd ed. Person Merrill Prentice Hall: Upper Saddle River, NJ.

Moreno, R., and Mayer, R. E. (2000). Engaging students in active learning: the case for personalized multimedia messages. J. Educ. Psychol. 92, 724-733.

National Research Council (NRC) (2003). BIO2010, Transforming Undergraduate Education for Future Research Biologists. Washington, DC: National Academies Press.

NRC (2009). A New Biology for the 21st Century: Ensuring the United States Leads the Coming Biology Revolution, Washington, DC: National Academies Press.

Nelson, K. C., Marbach-Ad, G., Fagan, W. E., Thompson, K., and Shields, P. (2009). MathBench biology modules: using interactive web-based modules to infuse mathematics into the undergraduate biology curriculum. J. Coll. Sci. Teaching 38, 34-39.

Parker, L. E., and Lepper, M. R. (1992). Effects of fantasy context on children's learning and motivation: making learning more fun. J. Pers. Soc. Psychol. 62, 625-633.

Project Kaleidoscope (2006). Report on Reports II: Recommendations for Urgent Action; Transforming America's Scientific and Technological Infrastructure. www.pkal.org/documents/ ReportOnReportsII.cfm (accessed 22 July 2010).

Ragosta, M., Holland, P.W., and Jamison, D.T. (1982). ComputerAssisted Instruction and Compensatory Education: The ETS/ LAUSD study. Princeton NJ: Educational Testing Service.

Robertson, E. B., Ladewig, B. H., Strickland, M. P., and Boschung, M. D. (1987). Enhancement of self-esteem through the use of computer-assisted instruction. J. Educ. Res. 80, 314-316.

Roblyer, M. D., Castine, W.H., and King, F. J. (1988). Assessing the Impact of Computer-based Instruction: A Review of Recent Research. New York: Haworth Press.

Ross, S. M. (1983). Increasing the meaningfulness of quantitative material by adapting context to student background. J. Educ. Psychol. 75, 519-529.

Steen, L.A. (2005). The "gift" of mathematics in the era of biology. In: Math \& Bio 2010: Linking Undergraduate Disciplines, ed. L.A. Steen, Washington DC: Mathematical Association of America.

Weglinsky, H. (1998). Does It Compute? The Relationship between Educational Technology and Student Achievement in Mathematics. Princeton, NJ: Educational Testing Service.

Yuan, R. (2005). A quantitative approach to the biology curriculum: issues to consider. In: Math \& Bio 2010: Linking Undergraduate Disciplines, ed. L.A. Steen, Washington DC: Mathematical Association of America, 27-33. 